\title{
A VIOLÊNCIA SEXUAL PRATICADA CONTRA CRIANÇAS E ADOLESCENTES: DESMISTIFICANDO A LÓGICA INDIVIDUAL DO PROCESSO VITIMIZATÓRIO
}

\author{
SEXUAL VIOLENCE AGAINST \\ CHILDREN AND ADOLESCENTES: \\ DEMYSTIFYING THE INDIVIDUAL LOGIC OF THE VICTIMIZATION PROCESS
}

SCHIRLEY KaMILE PAPLOWSKI1

\section{RESUMO}

O presente artigo tem como temática a violência de natureza sexual perpetrada contra o público infantojuvenil, com consideráveis intercorrências no país brasileiro nos últimos anos. Justifica-se pela abrangência do tema e pela conexão com distintos segmentos da vida humana, através dos impactos causados pelo evento traumático. A problemática do estudo se concentra na demonstração das raízes sociais da violência sexual, pela hipótese de sê-la manifestação da violência de gênero e das relações de poder e de dominação estabelecidas nos seios das sociedades, sem desconsiderar o papel psicológico da conduta (individual). Para enfrentar uma realidade que se apresenta tímida, embora com acentuada frequência, faz-se necessário descobri-la, cuja visibilidade é possível inclusive pelo debate e pela pesquisa acadêmica, objetivos deste estudo. Através do método hipotético-dedutivo, com técnica de pesquisa exploratória, o artigo foi dividido em três momentos, chegando às considerações de que a sociedade brasileira convive com o paradoxo da proteção legal de crianças e adolescentes, ao mesmo tempo em que fomenta a adultização, a espetacularização dos seus corpos (especialmente os femininos) e a culpabilização das vítimas, notavelmente nos casos de violência sexual.

Palavras-chave: Abuso sexual. direitos humanos infantojuvenis. espetacularização dos corpos. pedofilia. prática social.

1 Mestranda do Programa de Pós-Graduação Stricto Sensu em Direito (Mestrado em Direitos Humanos), da UNIJUí (Universidade Regional do Noroeste do Estado do Rio Grande do Sul). Aluna bolsista do programa Capes/PROSUC. Bacharela em Direito pela UNIJUÍ (2019). Integrante do Grupo de Pesquisa "Direitos Humanos, Justiça Social e Sustentabilidade" (CNPq/ UNIJUí). ORCID iD http://orcid.org/0000-0003-3503-967X. Lattes: http://lattes.cnpq.br/4774145225357211. E-mail: schirleykamile@hotmail.com. 
This article focuses on sexual violence perpetrated against children and adolescents, with considerable complications in Brazil in recent years. It is justified by the scope of the theme and the connection with different segments of human life, through the impacts caused by the traumatic event. The problem of the study focuses on the demonstration of the social roots of sexual violence, on the hypothesis that it is a manifestation of gender violence and the relations of power and domination established within societies, without disregarding the psychological influence of (individual) conduct. To face a reality that appears timid, albeit with accentuated frequency, it is necessary to discover it, whose visibility is possible even through the debate and academic research, objectives of this study. Through the hypothetical-deductive method, with exploratory research technique, the article was divided into three moments, reaching the considerations that Brazilian society coexists with the paradox of the legal protection of children and adolescents, at the same time that it promotes adultization, the spectacularization of their bodies (especially the female ones) and the blaming of the victims, notably in cases of sexual violence.

Keywords: Sexual abuse. human rights of children and adolescents. spectacularization of bodies. pedophilia. social practice.

\section{INTRODUÇÃO}

O espaço familiar, formado através da instituição histórica que é a família, é um campo no qual são praticadas múltiplas relações, cuja extensão, hoje, ultrapassa os modelos historicamente definidos como ideais. Na contemporaneidade, os laços que compõem a instituição se sustentam através do afeto, o que possibilitou reconhecer as relações homoafetivas e monoparentais (exemplificativamente) como autênticos sinônimos de família. No entanto, é dentro dessa mesma estrutura cultural que maiores conflitos podem surgir, sobretudo na ocorrência de desigualdade de direitos e deveres, atrelados ao uso da força e da violência. Quando se desvela a ocorrência de abusos no ambiente familiar - justamente no qual busca-se proteção, afeto e acolhimento - retratos nefastos emergem na forma de violência infantojuvenil, violência conjugal e violência contra idosos (POTTER, 2016).

Neste estudo, a atenção é destinada para a primeira espécie de violência antes mencionada, a qual ocorre no ambiente familiar, assim como fora dele. Sua prática pode se dar de variados modos, a exemplo de maus-tratos, abandono e negligência, e também de forma sexual, sendo esta o ponto crucial que aqui se acolhe. Este fenômeno comporta distintas maneiras, que ultrapassam a esfera imediata da noção de estupro, como pela divulgação de vídeo que contenha cenas de pornografia envolvendo criança ou adolescente. Por mais que tais casos aparentem não ocorrer na mesma intensidade que outros crimes, como os que atingem bens jurídicos patrimoniais, a percepção é ilusória e se deve, em grande medida, por uma das características que reveste tal forma de violência: ela ocorre dentro de dimensões que não permitem sua visibilidade, seja pela natureza do fato, seja pelo segredo familiar.

Aportados tais elementos iniciais, o presente artigo tem como temática a violência de natureza sexual perpetrada contra o público infantojuvenil, com consideráveis intercorrências no país brasileiro nos últimos anos. Sua justificativa nasce da abrangência do tema, a ponto de sê-lo um verdadeiro fenômeno (negativo), por causar dor e sofrimento às suas vítimas; bem como pelas dimensões a ele relacionadas, que incluem um conjunto de necessidades humanas tolhido pelo ato violento. 
Para tanto, o método de pesquisa adotado é o hipotético-dedutivo, na linha do proposto por Karl Popper (MARCONI; LAKATOS, 2003). A presente investigação comporta uma lacuna no conhecimento científico, um problema para conduzir a investigação, seguindo de sua hipótese (solução provisória), a qual é confirmada, recusada ou corroborada ao fim. In casu, o problema orientador da pesquisa consiste em: as causas da violência sexual contra meninos e meninas, especialmente no Brasil, são de ordem individual (como patologias psíquicas)? A hipótese construída e confirmada em resultados é de que, embora fatores individuais interfiram no agir violento das pessoas, as causas sociais são essenciais para a manutenção do atual estado violentador, tendo por base o modo pelo qual a sociedade banaliza a sexualização infantil, estimula a exposição de corpos (sobretudo femininos), adultiza e culpabiliza as vítimas. Diga-se, também, que no processo vitimizatório a sociedade acaba ocupando o papel de revitimizadora, porque amplia o trauma vivido pela vítima da violência, em função de perquirições, de culpabilização e da omissão protetiva.

Processo vitimizatório ou vitimização consiste no ato complexo pelo qual alguém é eleito à condição de objeto-alvo, em face do qual condutas são praticadas. Nesse processo, há formas de vitimização - ou modalidades de objetificação dos sujeitos - que se desdobram em primária, secundária e terciária. Tais formas estão relacionadas com o momento da violência e de quem a pratica. A vitimização primária consiste na primeira fase do processo traumático, que ocorre pela prática do fato, do crime; é a esfera imediata desse processo, a "violência primeira" (MOROTTI, 2017; PAPLOWSKI, 2018).

A secundária se refere ao sofrimento gerado pelo próprio sistema legal, diante do uso inadequado de procedimentos investigativos ou de atendimento, por exemplo, protagonizados por unidades escolares, conselhos tutelares, equipes assistenciais, Poder Judiciário (entre outros). Essa forma de vitimização também é reconhecida como revitimização, porque amplia o trauma vivenciado, dilata a vitimização e viola, em consequência, os direitos fundamentais de quem já foi ofendido. A vitimização terciária, por sua vez, trata-se da circunstância em que o sofrimento é praticado pela sociedade, especialmente na estigmatização e culpabilização da vítima (PAPLOWSKI, 2018; POTTER, 2016).

Para alcançar tais considerações, a técnica de pesquisa é exploratória (abarcando doutrinas, notícias, recortes artísticos e decisão judicial, mediante a coleta prévia de conteúdos pela autora), sem efetuar um estudo de caso em específico. A fim de narrar o status do país brasileiro de protetor legal da infância e juventude e também das responsabilidades sociais envolvidas, a técnica de pesquisa igualmente compreendeu observar dispositivos normativos, a exemplo da Constituição Federal de 1988 e das Leis Federais de n. 13.431/2017, 11.340/2006 e 8.069/90, dividindo o estudo em três momentos.

A violência sexual como prática social vem revelada no estudo através de sutis demonstrações, sobretudo através dos meios de comunicação, como na mídia televisiva e em letras musicais. Para combater esse cenário, além de desmistificar tabus que revestem o tema, importa debater e pesquisar o impasse, objetivos reais da investigação, a fim de promover o diálogo consciente do papel de cada ser humano na geração e na interrupção de violência, especialmente porque consumidores de produtos e serviços que, no mais das vezes, fomentam-na contra crianças e adolescentes. 


\section{A VIOLENCIA COMO UM FENÔMENO HISTÓRICO, BIOPSICOSSOCIAL E REPRESSOR DE NECESSIDADES}

Cotidianamente, contextos íntimos e de afeto provocam, no espaço das relações interpessoais, profundo padecimento. Entretanto, o espaço social também atua como sujeito ativo em relações de violência, em especial quando é culpabilizador da vítima, intolerante e omisso às múltiplas e constantes ações violentas dirigidas contra crianças e adolescentes. No plano normativo, sua condição de violentadora decorre da omissão no dever constitucional estabelecido pelo artigo 227, caput, da Constituição Federal da República, de 1988 (com redação dada pela Emenda Constitucional nº 65, de 2010):

É dever da família, da sociedade e do Estado assegurar à criança, ao adolescente e ao jovem, com absoluta prioridade, o direito à vida, à saúde, à alimentação, à educação, ao lazer, à profissionalização, à cultura, à dignidade, ao respeito, à liberdade e à convivência familiar e comunitária, além de colocá-los a salvo de toda forma de negligência, discriminação, exploração, violência, crueldade e opressão. (BRASIL, 2020, s.p., grifou-se).

Viver livre de tratamento cruel, explorador e opressivo é direito inerente a todo ser humano, inclusive com positivação expressa assegurada pelo Estatuto da Criança e do Adolescente, Lei Federal de n 8.069/1990, em seu artigo quinto². No entanto, embora seja vedada qualquer ofensa a direitos fundamentais, notadamente quanto aos infantojuvenis, 0 plano prático não é de alento $^{3}$. Dessa forma, a partir do momento em que outrem se comporta com violência dirigida ao infante, além de violar direito seu de viver livre de qualquer tratamento, o agente acaba de reprimir diversas necessidades do violentado, dentre elas a de integridade física e de liberdade pessoal (BARATTA, 1993). É através desta compreensão de violência que podemos relacioná-la como uma forma de anular o outro enquanto sujeito.

Além das múltiplas omissões verificáveis na sociedade, enquanto suposto agente protetor da infância e da adolescência, muitas das bases sociais perpassam por complexos processos de desestruturação, ou, ao revés, recentemente tornaram-se visíveis essas questões. Com a família não é diferente (e se diz isso não porque a lógica de família tradicional vem sofrendo modificações, o que é significativamente positivo e humanitário, mas porque é a partir da estrutura familiar que reiterados problemas de ordem psíquica e social surgem).

Sobre o assunto, Luciane Pötter (2016) observa que a violência contra crianças e adolescentes não é recente, ao contrário, que acompanha a história da humanidade, manifestando-se de diversas formas: "[...] quanto mais retroagirmos na história (e até atualmente em alguns povos) maiores são as chances de observarmos que a violência contra crianças

2 "Art. $5^{\circ}$ Nenhuma criança ou adolescente será objeto de qualquer forma de negligência, discriminação, exploração, violência, crueldade e opressão, punido na forma da lei qualquer atentado, por ação ou omissão, aos seus direitos fundamentais" (BRASIL, 2020, s.p.).

3 Inobstante o segredo ser uma das características da prática do abuso sexual, mais especificamente quando intrafamiliar, há situações em que os atos de violência sexual se tornam nítidos ao conhecimento público. E é a partir dessas intercorrências que a assiduidade com que crianças e adolescentes são vitimizados sexualmente torna-se perceptível. Apenas no mês de setembro de 2017 (em um dos semestres da condução da pesquisa), de forma exemplificativa, dois grandes fatos ocorreram no estado do Rio Grande do Sul e se tornaram públicos. Ambos ocorreram na capital gaúcha: um deles em um supermercado, ocasião na qual o autor do fato, contando mais de 62 anos, se aproximou da infante e tocou partes do corpo da menina, sendo todos os atos praticados registrados pela câmera de vigilância do local (PAGANELLA, 2017). 0 outro, por sua vez, se deu de forma virtual, ocasião na qual um estudante do curso de medicina (de 27 anos) detinha em sua casa um computador contendo mais de 12 mil fotografias de crianças e adolescentes em situação de pornografia, sendo o objeto apreendido mediante cumprimento de mandado de busca e apreensão (SPERB, 2017). 
e adolescentes e a falta de proteção jurídica eram (e são) comuns" (PÖTTER, 2016, p. 68). Nas palavras da autora, especificamente com relação à violência sexual, surge o que se reconhece por "incesto", o qual "[...] pode ser a forma mais extrema de abuso sexual, envolvendo relações de um adulto com uma criança ou adolescente em âmbito familiar" (PÖTTER, 2016, p. 68).

Diante do pacto de silêncio que com frequência impera nos contextos de violência sexual intrafamiliar, grande parte dos nefastos atos de abuso foram (e continuam sendo) ocultados. A disfuncionalidade familiar, nesse contexto, surge em oposição à ótica pela qual a família é visualizada, como sendo o espaço sagrado e harmônico, o "lar, doce lar". A disfuncionalidade permite ver esta estrutura como promotora de dor, sem qualquer condição de efetivar a existência sadia e digna de seus membros. Entrecruzam-se, assim, afeto e violência, cujas consequências dificilmente poderão ser medidas, cenário que requer a reunião de distintas áreas de estudo para o seu enfrentamento (como a Psicologia, o Serviço Social, a Sociologia e o Direito). 0 estupro surge nesse espaço como expressão máxima da violência sexual, por vezes acompanhado pela pedofilia.

Maria Cecília Minayo (1994) leciona que a violência é um dos problemas que há muito tempo perpassam a teoria social e a prática política e relacional da humanidade. "Não se conhece nenhuma sociedade onde a violência não tenha estado presente" (MINAYO, 1994, p. 7). Em verdade, atualmente, situações que retratam condutas violentas causadoras de extrema repugnância têm se tornado mais visíveis, como é o caso do tema em estudo. No entanto, a exemplo de comportamentos agressivos, a história dos povos da humanidade confere o conhecimento de sua presença desde períodos remotos.

Tal violência não está relacionada apenas a um ramo científico, porquanto se expressa no campo jurídico, social, filosófico e psicológico. A busca pelo entendimento da essência do fenômeno da violência é de longa data, conforme explica a autora; todavia, hoje é praticamente unânime a ideia de que a violência não é inerente à condição humana e que não tem raízes biológicas. "Trata-se de um complexo e dinâmico fenômeno biopsicossocial, mas seu espaço de criação e desenvolvimento é a vida em sociedade. Portanto, para entendê-la, há que se apelar para a especificidade histórica" (MINAYO, 1994, p. 7). A somar na classificação da violência como um fenômeno biopsicossocial, o jurista italiano Alessandro Baratta (1993) a compreende como repressão de necessidades, em qualquer das suas formas, e violação ou suspensão de direitos humanos.

A filósofa brasileira Marilena Chaui (2019, s.p.) assimila a temática de violência com ética. Isso porque são diametralmente opostas: a ética compreende o sujeito enquanto ser racional e livre, ao passo em que a violência o simplifica enquanto coisa, por desconsiderar sua vontade e liberdade. Em suas palavras:

[...] A violência se opõe à ética porque trata seres racionais e sensíveis, dotados de linguagem e de liberdade como se fossem coisas, isto é, irracionais, insensíveis, mudos, inertes ou passivos. Na medida em que a ética é inseparável da figura do sujeito racional, voluntário, livre e responsável, tratá-lo não como humano e sim como coisa, fazendo-Ihe violência nos cinco sentidos em que demos a esta palavra. (CHAUI, 2019, s.p.).

Assim sendo, Chaui (2019) e Baratta (1993) convergem em suas considerações por relacionarem a violência como forma de imposição, cuja conduta desconsidera a condição 
humana do sujeito violentado, detentor de direitos, racionalidade, vontade e dignidade. De fato, o desenvolvimento da espécie humana acompanha grandes eventos pautados por atrocidades. É por tais motivos que a violência é considerada e comumente denominada como um fenômeno, de tamanha extensão que se expressa no plano universal, não se restringindo a uma determinada época ou sociedade. Considerando a multiplicidade de relações estabelecidas entre os indivíduos e a dinâmica social que daí decorre, estando nela inserida a violência como um fato persistente e complexo, não restrito a um grupo social ou período da história, depreende-se que a violência é considerada um fenômeno social, não relacionado à natureza humana individual e biológica, mas à coletividade.

A violência sexual, como ponto nevrálgico de abordagem nesta investigação, ultrapassa o ato do estupro e adentra em teias mais sutis. Normativamente, há no Brasil (2020), por intermédio da Lei n 11.340 de 2006, também conhecida como Lei Maria da Penha, menção aos distintos modos pelos quais a violência sexual é perpetrada, quais sejam:

Art. $7^{\circ}$. São formas de violência doméstica e familiar contra a mulher, entre outras: [...] III - a violência sexual, entendida como qualquer conduta que a constranja a presenciar, a manter ou a participar de relação sexual não desejada, mediante intimidação, ameaça, coação ou uso da força; que a induza a comercializar ou a utilizar, de qualquer modo, a sua sexualidade, que a impeça de usar qualquer método contraceptivo ou que a force ao matrimônio, à gravidez, ao aborto ou à prostituição, mediante coação, chantagem, suborno ou manipulação; ou que limite ou anule o exercício de seus direitos sexuais e reprodutivos. (BRASIL, 2020b, s.p.).

O contexto que envolve crianças e adolescentes é mais específico, abarcando diversas condutas que atingem a integridade sexual daqueles, relembrando também que essa natureza de infração possui uma intensa potencialidade lesiva no aspecto psicológico, tendo em vista que, além de toda a repugnância que o fato por si só já causa, as vítimas são pessoas notadamente frágeis (seja pela tenra idade, condição física ou pelo estágio de desenvolvimento).

Ao traçar um paralelo sobre tal fenômeno com questões de gênero, o enlace aparenta ser equivocado, ao menos em uma visão mais simplista. Isso se deve à crença de que a abordagem de gênero se restringe a pessoas adultas, em típicas relações de violência doméstica e familiar. Entre esses dois mundos que habitam a vida social (o infantil e o não infantil), coexistem as significativas relações de poder, responsáveis pelo liame entre a violência e o gênero, em parcela considerável dos casos.

É desde a tenra idade que típicas manifestações tendenciais de gênero são impostas, muitas delas encobertas por "naturalidade". Consistem em um conjunto simbólico ordenado 4 de comportamentos, preferências, brincadeiras, cores (e até mesmo a expectativa de atividades tida como "obrigatórias"), que diferenciam meninas e meninos em direitos e deveres.

4 O sentido e o termo simbólico, como poder, provêm dos estudos desenvolvidos pelo sociólogo Pierre Bourdieu (1989), ao analisar as relações informais de poder. O poder simbólico assume uma condição de invisibilidade, presente nas entrelinhas das relações sociais. Ele opera através de sistemas também simbólicos, a exemplo da língua, e de símbolos (por sentidos e representações). Os símbolos fazem parte de como a realidade e o mundo são vistos, inclusive pela repetição, entendidos como "[...] elementos que, no sentido antropológico, produzem sentidos e significados no campo social, de modo que criam 'integração social' [...]" (BURCKHART, 2017, p. 208-209) e consensos sobre uma ordem na sociedade. "A reprodução é a condição pela qual o simbólico se difunde, produzindo seus efeitos em grande escala" (BURCKHART, 2017, p. 209), criando o que Bourdieu denomina de habitus. Através deles, valores são consolidados e integram a cultura, o que pode produzir instrumentos de dominação e sua legitimação, especialmente no recorte de gênero nas sociedades patriarcais. Para aprofundamento acerca deste poder, consultar a obra "O poder simbólico", de Pierre Bourdieu (1989). 
Campanhas para combater a desigualdade de gênero na infância são realizadas com empenho pela organização não-governamental "Plan International", a qual defende os direitos de crianças, adolescentes e jovens, no Brasil, desde 1997, desenvolvendo campanhas com foco na promoção da igualdade de gênero, combatendo, assim, diversas formas de violências praticadas contra infantojuvenis.

Em pesquisa do Coletivo Não Me Kahlo, acerca da construção da feminilidade, elencou-se dados de estudo realizado pela Plan International Brasil, verificando que desde a tenra idade "as meninas aprendem que devem cuidar da casa, enquanto seus irmãos estão brincando, assistindo TV ou estudando, elas estão lavando louça, arrumando as camas ou ganhando sua primeira vassourinha". A pesquisa também considerou dados concretos sobre a realidade do país: "Um estudo realizado com brasileiras de 6 a 14 anos concluiu que 81,4\% delas arrumam a sua própria cama, enquanto apenas $11,6 \%$ dos meninos fazem o mesmo. Elas não só dedicam mais tempo à tarefa, como são cobradas de forma desigual" (LARA; RANGEL; MOURA; BARIONI; MALAQUIAS, 2016, p. 17).

Essas disparidades são acentuadas na vida adulta, na qual múltiplas relações domésticas e familiares são demarcadas pela submissão da mulher e independência do homem. Constrói-se um espaço intrafamiliar ao exercício do poder pela figura masculina, alicerçado por remotas construções sociais e culturais, iniciadas na fase infantil e reforçadas na vida adulta.

Dados do Boletim Epidemiológico do Governo Federal (BRASIL, 2018) afirmam a presença majoritária da figura masculina na condição de violentador sexual de crianças e adolescentes, o que reforça a importância de inserir gênero nesta discussão. 0 autor da violência, neste caso, vale-se do abuso para manifestar o poder e o domínio sobre um corpo. A especificidade que reveste o caso infantojuvenil é de o violentado ser severamente vulnerável, sobretudo em condições físicas e psíquicas, enquanto criança ou adolescente. 0 abuso sexual consiste, pois, na forma máxima de dominação pela figura masculina,

ou seja, contrariando a vontade da mulher ou da criança, o homem mantém relações sexuais, provando assim, sua capacidade de submeter à outra parte (seja ela crianças ou adultos) à dominação. Em outras palavras, o homem submete a criança a relações sexuais de submissão, provando assim a ideologia dominante em que ela não tem direito de desejar e o direito de escolha. [...] Impotentes quanto a sua situação, a única saída que encontram para exercer seu poder de macho é contra aqueles que se encontram em posição inferior à sua, não somente econômica, mas de gênero. (SANFELICE, 2011, p. 93).

A compreensão de Gênero se designa também pela identificação social, que pode transcender a classificação binária entre feminino e masculino. A partir dessa forma de identificação dos sujeitos, construiu-se a sistemática pautada pela desigualdade entre direitos e deveres, inicialmente através da divisão do trabalho (DUSSEL, 2013). Tal divisão ainda está presente na sociedade brasileira, na qual, pelo fato de ser menina ou mulher, muitos obstáculos surgem para a efetivação de direitos fundamentais. Também advém papéis estipulados, na forma de estereótipos, consignando que determinados comportamentos, acessos e direitos se concentram em uma figura: a masculina.

Em pesquisa realizada por Monique Soares Vieira (2016) acerca da violência sexual infantojuvenil, ressaltou-se que as desigualdades se acentuaram com o sistema econômico 
capitalista, o qual conduziu à banalização do ser humano e a desumanização das relações pessoais. Quanto à violência sexual, pontuou a sua naturalização, decorrente de um sistema patriarcal (no qual o agente dominador, dotado de autoridade, concentra-se na figura do homem); ainda, a objetificação da criança e do adolescente, como propriedade da família. Recentemente, essa visão sobre o infante vem sendo modificada, sobremaneira no plano legal com o advento do Estatuto da Criança e do Adolescente. Por outro lado, persiste uma ótica que desconsidera a constituição psíquica da criança e do adolescente, tornando-os facilmente submissos, dominados e coisificados. Ou seja, essas duas visões estão presentes hoje: uma protetiva e outra violadora.

Observa-se que a violência interindividual (da qual a sexual é exemplo mais radical) não é resultado exclusivo de personalidades desajustadas, violentas ou abusivas. Em grande medida ela reflete a cultura de violência (em quaisquer de suas formas) presente na sociedade, na qual o outro, por não ser visto como um igual, a despeito de suas diferenças, torna-se objeto de controle, de poder, de dominação. Outrossim, ressalta-se que não se está a delimitar que apenas meninas são alvo de violência na sua forma sexual; no entanto, cotidianamente, relatos, índices e noticiários enfatizam que as desigualdades de gênero afetam crianças e adolescentes do sexo feminino com incidência muito superior que aquelas do sexo masculino.

\section{A VIOLÊNCIA SEXUAL COMO MANIFESTAÇÃO DE PODER, NÃO DE DESEJO: A CULTURA DO ESTUPRO}

"Nunca ninguém sabe se estou louco para rir ou para chorar... Por isso o meu verso tem esse quase perceptível tremor... A vida é triste, o mundo é louco! Nem vale a pena matar-se por isso. Nem por ninguém. Por nenhum amor... A vida continua, indiferente!" (QUINTANA, 2005, p. 114). Nunca se trata de um dos poemas que integra a obra "A cor do invisível", de Mario Quintana. 0 escrito se compatibiliza com o tema sob análise, na medida em que o encontro cotidiano com relatos de violência sexual faz crer que o mundo efetivamente é "louco", e a vida, para quem sofre as dores e marcas indeléveis dessa violência, certamente é triste, desumana e indiferente.

Dentre o arcabouço da violência sexual, o estupro é a forma mais conhecida. É o representativo desta espécie de violência, portadora das características de ser repugnante, doentia, vilipendiosa e dolorosa, ao mesmo tempo que indescritível e traumática. Apesar disso, sua prática não só é comum, como banalizada, a ponto de se afirmar a existência de uma "cultura do estupro", em ambos os sentidos que a expressão permite. A cultura do estupro mostra-se presente em um contexto que, de tão corriqueiros e frequentes os casos, a sua prática passa a ser naturalizada. Por outro viés - que não desconsidera a anterior, mas a complementa -, a expressão corresponde à culpabilização das vítimas de tais atos, porquanto a violência sexual se insere supostamente em um comportamento próprio de homens (NIELSSON; WERMUTH, 2018).

Nielsson e Wermuth (2018) analisam a presença massiva da violência sexual no país, tanto hoje quanto no passado. A saber, desde o período em que as terras tupiniquins foram 
colonizadas, com o abuso de mulheres indígenas, seguidas por aquelas que foram forçadas a ingressar no território. Inobstante o fato de que esse cenário não se alterou na atualidade, em suas verdadeiras raízes, a conclusão de que "estuprar" integra a lógica cultural não é oriunda do Brasil, cujo termo "[...] foi utilizado pela primeira vez por feministas norte-americanas na década de 1970 e sugere que determinada sociedade cultiva crenças e convenções que naturalizam a violência sexual contra as mulheres" (NIELSSON; WERMUTH, 2018, p. 174).

$\mathrm{O}$ ato de estuprar mostra-se presente de maneira individual e coletiva, sendo considerada, esta última, uma característica coletiva que denuncia o estupro como caráter cultural, na acepção da antropóloga Debora Diniz, professora da Universidade de Brasília (COLLUCCI, 2017). Dados do Ministério da Saúde divulgados pelo jornal Folha de São Paulo dão conta de que, no Brasil, por dia, são praticados em média, dez estupros coletivos. Acre, Tocantins e Distrito Federal lideram as taxas por cem mil habitantes (COLLUCCI, 2017). Todavia, as conclusões da pesquisa podem ser ainda mais alarmantes, tendo em vista o fato de que as ocorrências desta natureza muitas vezes não chegam ao conhecimento dos órgãos públicos (ao que se reconhece por subnotificação). São seus possíveis fatores: a culpabilização da vítima, sobretudo em crimes sexuais (como uma das circunstâncias que reprimem o registro policial do fato); a violência praticada pelo próprio aparato público, na forma de produção da prova; sem olvidar da tolerância social (COLLUCCI, 2017; PAPLOWSKI, 2018).

Segundo Daniel Cerqueira, pesquisador do Ipea (Instituto de Pesquisa Econômica Aplicada), esses dados são apenas uma parcela das efetivas ocorrências: "infelizmente, é só a ponta do iceberg. A violência sexual contra a mulher é um crime invisível, há muito tabu por trás dessa falta de dados" (COLLUCCI, 2017, s.p.). E complementa: "Muitas mulheres estupradas não prestam queixa. Às vezes, nem falam em casa porque existe a cultura de culpá-las mesmo sendo as vítimas" (COLLUCCI, 2017, s.p.). À semelhança do que ocorre com mulheres adultas, repete-se em face de crianças e adolescentes, por um conjunto complexo e multifacetado de motivos, a exemplo do medo, da culpa, da falta de compreensão da realidade e também da síndrome do segredo. Reconhecer esta circunstância corresponde a reconhecer, igualmente, que os números podem ser mais elevados.

A perpetração do estupro em geral, do ano de 2011 a 2016, praticamente dobrou no Brasil. Em 2011, foram registrados cerca de 12.087 casos a partir de dados de unidades de saúde. Em 2016, esse número chegou a 22.804 (COLLUCCI, 2017). Em Nota Técnica divulgada pelo Ipea em março de 2014, a partir da análise de registros do Sistema de Informação de Agravos de Notificação (SINAN), gerido pelo Ministério da Saúde, constatou-se que anualmente ocorrem em média 527 mil tentativas ou casos de estupros consumados no país, dos quais $10 \%$ são reportados à polícia (CERQUEIRA; COELHO, 2014). Evidencia-se, novamente, a margem de desconhecimento quantitativo real de violência sexual que ocorre no país brasileiro, o que causa maior necessidade de discutir a temática. Observa-se também a possível proporção absurda de casos do tipo, circunstância desprovida de paralela discussão social, exceto determinados casos que são reconhecidos como o ápice.

O número especulado pelo Ipea (de 527 mil ocorrências) é extremamente grave e revela que, em uma hora, cerca de sessenta pessoas são vítimas da tentativa ou da consumação do estupro no Brasil. A mesma pesquisa apontou que, dentre as pessoas vitimizadas, aproximadamente $90 \%$ dos casos são mulheres; quanto à idade das vítimas, $70 \%$ são crianças ou adolescentes (apenas 30\% contam idade superior a 18 anos). Ainda, indicou que "a maio- 
ria esmagadora dos agressores é do sexo masculino, independentemente da faixa etária da vítima, sendo que as mulheres são autoras do estupro em $1,8 \%$ dos casos, quando a vítima é criança" (CERQUEIRA; COELHO, 2014, p. 9). As circunstâncias de gênero que demarcam majoritariamente as vítimas e os agressores convergem à discussão sobre de que maneira estereótipos de gênero influenciam no comportamento e na vida das pessoas na sociedade hodierna.

Estima-se que durante a infância e a juventude os agressores são aqueles que mantêm maior contato com a criança ou o adolescente, justamente quem possui relação de afeto e/ou de familiaridade com o violentado. Entretanto, o cenário se modifica no decorrer do desenvolvimento etário da pessoa vitimizada:

[...] 24,1\% dos agressores das crianças são os próprios pais ou padrastos e que $32,2 \%$ são amigos ou conhecidos da vítima. 0 indivíduo desconhecido passa a configurar paulatinamente como principal autor do estupro à medida que a idade da vítima aumenta. Na fase adulta, este responde por $60,5 \%$ dos casos. No geral, $70 \%$ dos estupros são cometidos por parentes, namorados ou amigos/conhecidos da vítima, o que indica que o principal inimigo está dentro de casa e que a violência nasce dentro dos lares. (CERQUEIRA; COELHO, 2014, p. 9).

Desta perspectiva, é nítida a constante relação de proximidade que o autor da violência sexual possui com a pessoa ofendida, sobretudo quando a vítima é infante. Com frequência, os agressores registram a violência na forma de vídeos e fotografias, como se a horrenda prática fosse um mérito. A culpa, dor e vergonha recaem, ao contrário, na pessoa ofendida, ao passo que o violentador demonstra exercer o controle do corpo de outrem sem remorso. O meio social, ao tomar conhecimento de tais fatos age como perquiridor das causas da violência, mas, paradoxalmente, questiona os hábitos, as vestimentas e o comportamento da própria pessoa violentada, majoritariamente do sexo feminino. "Chamamos isso de culpabilização da vítima, comportamento diretamente relacionado à cultura do estupro" (LARA, RANGEL; MOURA; BARIONI; MALAQUIAS, 2016, p. 164).

Lara, Rangel, Moura, Barioni e Malaquias (2016) analisam a violência sexual contra a mulher como uma violência simbólica, através da qual o estupro não se manifesta diretamente, mas por intermédio de hábitos, de discursos que justificam e toleram determinados atos de abuso. Essa cultura (co)existe em um país que criminaliza a sua prática, inclusive como crime hediondo, alvo de repressão mais severa. Sustentam as autoras que, tal como a violência doméstica, o estupro é apenas o extremo visualizado, ou seja, a ponta do iceberg, "cuja parte submersa e que dá sustentação a tudo isso são violências sutis, naturalizadas e reproduzidas no senso comum" (LARA, RANGEL; MOURA; BARIONI; MALAQUIAS, 2016, p. 165). São as mesmas condutas que, invisivelmente, reforçam a superioridade masculina sobre a feminina e intensificam, a partir de então, diversas práticas truculentas, ainda que não deixem vestígios materiais.

Pode-se dizer que o estupro representa antes o exercício de poder sobre o corpo do que a satisfação do desejo sexual. Dito de outro modo: que o estupro se assenta em questões sociais e culturais acima das de ordem psicológica. Nos contextos de violência sexual em face de infantojuvenis, "esta violência, manifesta, concretamente, uma relação de poder que se exerce pelo adulto ou mesmo não adulto, porém mais forte", em um "[...] processo de apro- 
priação e dominação não só do destino, do discernimento e da decisão livre destes, mas de sua pessoa enquanto outro" (FALEIROS, 1998, p. 43).

Por este mesmo prisma, Vera de Andrade (2005) defende que o desejo não se trata de elemento basilar à prática do estupro: "sabe-se, hoje, [...] que não se trata de conduta voltada, prioritariamente, para a satisfação do prazer sexual (lascívia desenfreada), como também preconiza o discurso criminológico e jurídico-penal oficial e o senso comum" (ANDRADE, 2005, p. 95-96). Igualmente pontua que o espaço no qual a violência sexual ocorre com maior frequência é dentro do espaço doméstico, no âmbito das relações previamente constituídas entre ofensor e ofendida, sendo o uso da sexualidade um modo de expressão de relações de poder. Prossegue e assinala que:

As mulheres começaram a dar-se conta de que o estupro (assim como os maus-tratos, o incesto, a prostituição, o assédio sexual no trabalho etc.) são fenômenos de uma estrutura de poder, a existente entre homens e mulheres, e o argumento da violência individual foi cedendo lugar ao argumento da violência estrutural. (ANDRADE, 2005, p. 96).

É assim que o retrato se repete. Mudam-se os personagens, mas o cenário é o mesmo: a violência sexual intrafamiliar (que também é perpetrada externamente às relações do núcleo) contra crianças e adolescentes ocorre há muito tempo. Sucede que a sua prática, desde o princípio, é velada, da mesma forma que pouca credibilidade se confere à palavra da criança, vista neste contexto como sedutora e maliciosa ou, ainda, como fantasiosa.

\section{ABUSO SEXUAL PRATICADO CONTRA O PÚBLICO INFANTOJUVENIL: ABORDAGEM DA PEDOFILIA E DE OUTROS CONCEITOS BÁSICOS}

Incontáveis pesquisadores(as) que estudam esta temática desejam em suas obras, de antemão, um mundo de mais amor e respeito às crianças e aos adolescentes. Não é novidade afirmar o reconhecimento doutrinário, legislativo e científico das peculiares condições de desenvolvimento sobre o público infantojuvenil. Não fosse o suficiente, a academia discute cotidianamente sobre seus direitos, todavia nem sempre sob os olhos da violência que sofrem, mas acerca de seu "plus" (compreendido como o acréscimo de proteção promovido pela doutrina da proteção integral). Em oposição ao debate, contudo, quanto ao fenômeno da violência sexual prepondera o silêncio. Anthony Giddens (2008), a respeito da visibilidade do problema, aduz que o abuso sexual infantil ganhou espaço de discussão nas últimas décadas e que, diante dos tabus atinentes à sexualidade, essa prática era pouco comum. Todavia, revelou um fato assustadoramente banal. $\mathrm{Na}$ atualidade, tanto o conhecimento da prática de violência sexual quanto a existência de mecanismos de proteção tornaram-se mais acessíveis pelos meios de comunicação em geral.

A compreensão da violência sexual contra o público infantojuvenil exige perpassar por conceitos básicos específicos, tais como o abuso, a exploração sexual e a pedofilia (objetivo específico desta seção). Isso será possível mediante a análise normativa (de lei em tese), jurisprudencial (de determinada decisão judicial), doutrinária (no âmbito da psicologia e do 
direito) e de notícias coletadas quando da realização da pesquisa (que compreende a produção de materiais jornalísticos).

A concretização da violência sexual se tem por aquilo que preferiu normativamente denominar de exploração e de abuso sexual, formas distintas daquela. A primeira possui íntima relação com a ideia de remuneração e de contraprestação, o que não afasta o caráter violentador da conduta, sobretudo se praticada contra o público aqui referido, levando-se em consideração as condições físicas e psíquicas de desenvolvimento de crianças e adolescentes. $O$ ato sexual, na exploração, é uma troca, que pode ser observada através de valores ou presentes, superobjetificando o infante. Com relação ao abuso, pode ser qualquer situação na qual o infante é utilizado "para gratificação sexual de outrem" (PÖTTER 2016, p. 97). Nesse cenário não há o caráter da criança como mercadoria (a exemplo do que ocorre na exploração sexual), mas como objeto para satisfação ou estimulação sexual adulta, geralmente ocorrendo em conjunto com violência psicológica, na forma de ameaças. A respeito, a Lei ${ }^{\circ}$ 13.431, de 04 de abril de 2017, em vigor desde abril de 2018 - que estabelece mecanismos para controlar a violência institucional (decorrente do processo de apuração da violência) -, distingue abuso de exploração sexual em seu artigo $4^{\circ}$, inciso III, in verbis:

Art. 4o Para os efeitos desta Lei, sem prejuízo da tipificação das condutas criminosas, são formas de violência: [...]

III - violência sexual, entendida como qualquer conduta que constranja a criança ou o adolescente a praticar ou presenciar conjunção carnal ou qualquer outro ato libidinoso, inclusive exposição do corpo em foto ou vídeo por meio eletrônico ou não, que compreenda:

a) abuso sexual, entendido como toda ação que se utiliza da criança ou do adolescente para fins sexuais, seja conjunção carnal ou outro ato libidinoso, realizado de modo presencial ou por meio eletrônico, para estimulação sexual do agente ou de terceiro;

b) exploração sexual comercial, entendida como o uso da criança ou do adolescente em atividade sexual em troca de remuneração ou qualquer outra forma de compensação, de forma independente ou sob patrocínio, apoio ou incentivo de terceiro, seja de modo presencial ou por meio eletrônico. (BRASIL, 2020c, s.p., grifou-se).

A respeito, vale pontuar a menção normativa que indica a caracterização da violência ainda que ela não se dê presencialmente, ou seja, se praticada por meio eletrônico (como nas redes sociais). Em ambas, na exploração ou no abuso, presente está o caráter de dominação e abuso de poder sobre os corpos infantojuvenis, os quais são submetidos a vontade e interesse do violentador, induzidos os forçados a manter a relação, ferindo o direito de viver em condições livres de qualquer comportamento violento, agressivo ou que ofenda a dignidade. "Trata-se de uma violação dos direitos humanos universais e dos direitos peculiares à pessoa em desenvolvimento, negando a ela o direito ao desenvolvimento sadio de sua sexualidade" (CHILDHOOD, 2017, s.p.). A tipificação penal da conduta lesiva depende do ordenamento jurídico vigente, que é regido pelo princípio da legalidade. Deve-se observar que a forma denominada de "abuso sexual" não é tipificada nacionalmente como crime. Trata-se, em verdade, de expressão para caracterizar diversos outros atos, como o estupro.

A pedofilia, por sua vez, não se trata por si só de norma criminalizadora, mas de um comportamento psíquico. Encontra-se no plano médico antes do plano jurídico. Para a 
doutrina psicanalítica, a pedofilia se caracteriza pelo desvio, distúrbio na conduta sexual. É referenciada, por vezes, como perversão, cujo termo inicialmente foi abordado por Sigmund Freud (CASTRO; BULAWSKI, 2011). A Organização Mundial da Saúde, em seu Cadastro Internacional de Doenças ${ }^{5}$ (CID 10), cataloga pedofilia como um transtorno de preferência sexual (F65.4). É da psicanálise que também se extrai a relação de pedofilia com a impotência do indivíduo, que sustenta um agir "pedofílico" para exercer sua sexualidade sobre outrem de maior vulnerabilidade. "Por se tratar de uma pessoa sexualmente inibida, o agente tende a escolher como parceiro uma pessoa vulnerável, possuindo sobre ela uma ilusão de potência" (CASTRO; BULAWSKI, 2011, p. 8). É dessa forma que exerce a ideia de domínio, controle e poder, sem a necessidade de efetivo contato ou ato sexual com o infante, bastando, para ser considerado clinicamente como pedófilo, o agente que nutre constante e obsessivo desejo, fantasias sexuais e/ou atração por crianças ou adolescentes (CASTRO; BULAWSKI, 2011).

Há que se observar, no entanto, que nem todas as pessoas que violentam sexualmente crianças e adolescentes são pedófilas, porquanto para assim incorrerem haverá de se fazer presente a patologia e seus elementos caracterizadores (tais como a reiteração de atos, atração sexual compulsiva e obsessiva por infantes e adolescentes, entre outros). Do mesmo modo, ser pedófilo não significa ser abusador, necessitando exteriorizar sua conduta e atingir direitos de outrem para assim ser caracterizado, seja através de contato físico ou virtual. Pontua-se que há pessoas portadoras do desvio sexual que, no decorrer de toda sua vida, jamais violaram a dignidade sexual de infantes, apenas nutrindo na sua esfera íntima a perturbação sexual.

Embora considerada doença, pairam constantes dúvidas a respeito da possibilidade de cura, cuja incidência doutrinária repousa na impossibilidade. Nessa toada, Denis Caramigo (2017) observa a inexistência de cura para a pedofilia e que, quem dela padece, "[...] deve ter acompanhamento clínico constante para que não exteriorize a sua patologia. Há de se dizer que nem todo pedófilo é um 'criminoso'. Só comete crime aquele que exterioriza a sua pedofilia" (CARAMIGO, 2017, s.p.).

Em uma rica análise social do fato, Jane Felipe (2012) estuda a pedofilia como prática social contemporânea, visivelmente no cenário nacional, na medida em que vige uma proteção normativa a crianças e adolescentes, ao mesmo tempo em que há a disponibilização dos seus corpos, sobretudo os femininos, como desejáveis (ao que denomina de espetacularização dos corpos e da sexualidade) - comportamento que se apresenta através de letras musicais, imagens editadas por revistas, meios de comunicação, dentre outros. Em suas palavras, são vislumbradas contradições que se mostram interessantes nas sociedades contemporâneas,

[...] pois ao mesmo tempo em que se criam leis que visam a proteger a infância e a adolescência contra os maus-tratos, a negligência, o abandono, a violência/abuso sexual, a exploração sexual e a pedofilia, por outro lado, essa mesma sociedade legitima determinadas práticas sociais, seja através da mídia - publicidade, novelas, programas humorísticos -, seja por intermédio de músicas, filmes etc., em que os corpos infantojuvenis são visibilizados

5 Classificação Estatística Internacional de Doenças e Problemas Relacionados à Saúde, ou CID, é o padrão internacional para registro, análise, comparação (dentre outros) de doenças e mortes. 0 documento é a base para identificar tendências e estatísticas de saúde a nível global, desenvolvido pela Organização Mundial da Saúde (OMS). Para cada estado de saúde é atribuída uma categoria única, que corresponde a um código. Uma nova versão entrará em vigor a partir de $2022\left(11^{\mathrm{a}}\right.$ versão) (OPAS, 2020). 
de forma extremamente erotizada, através de expressões, gestos, roupas e falas, modos de ser e de se comportar. Corpos que se colocam como objeto de desejo e de consumo. (FELIPE, 2012, p. 32).

A respeito, há o caso de "hipersexualização" da atriz Millie Bobby Brown, de 13 anos, integrante do elenco da série americana "Stranger Things" ${ }^{6}$. A menina, quando vista nas telas, apresenta-se como criança, iniciando seu período de adolescência. Contudo, seus perfis nas redes sociais, as capas de revistas que protagonizou e as imagens de divulgação da série denotam ser pessoa adulta, bem mais velha do que é aparentemente. A esse fenômeno dá-se o nome de "adultização", que é a antecipação do fim da infância. Em matéria elaborada pelo Coletivo Não Me Kahlo (ALVAREZ, 2017), que enfrentou a questão sob o ponto de vista crítico, foi possível identificar as questões específicas nas imagens de Millie, com vestimentas intencionalmente organizadas pela produção televisiva, objetivando aparentar ser pessoa adulta como forma de aceitação social. "Isso nos mostra como a indústria do entretenimento sutilmente incentiva a sexualidade infantil. Apesar de não ser de uma forma explícita, isso influencia crianças a sentirem a necessidade de serem sensuais" (ALVAREZ, 2017, s.p.).

O descompasso apontado pela educadora Jane Felipe (2012) torna-se facilmente perceptível, porquanto os avanços almejados a crianças e adolescentes em direitos e garantias acaba por camuflar o paradoxal contexto social que os sexualiza constantemente, além de imprimir-lhes o "desejo em ser adulto" como natural e típico de toda criança. E isso não se refere apenas à realidade brasileira, é um comportamento global. Há, neste passo, uma inversão de papéis, já que, para ser aceita socialmente (ressaltando a celeuma sobre os corpos femininos), deverão as garotas serem dotadas de comportamentos sexuais, polemicamente, de um corpo esbelto e atraente. Ou seja, é para a aceitação pelo público masculino, que o visualiza como um objeto de desejo e para satisfação de interesses pessoais.

A realidade local, a brasileira, também possui seus contextos de erotização precoce de meninas, como é o caso de Gabriella Abreu Severino (ou MC Melody). A menina, nascida no ano de 2007, é cantora dos estilos pop e funk, cuja ascensão no mundo da música se tornou um caso muito comentado, especialmente em 2015, quando contava a idade de oito anos. Apesar da pouca idade, Gabriella já se inseria em um universo adulto e sexual, gravando videoclipes nos quais cantava letras com alto teor sexual (DEBORA, 2018). A negligência familiar nesse sentido e o impacto individual e coletivo que a hipersexualização acarreta promovem visões deturpadas sobre a menina em si, assim como sobre as demais crianças, que compreendem um perfil de aceitação e tendem a reproduzi-lo. Consequentemente, infâncias são ceifadas pela conduta pessoal/social negligente, pelos meios de comunicação e pela "apreciação" de seu conteúdo pelo público.

Outro tema importante neste conjunto de debates é o incesto. Isso porque, ao apreciar dados estatísticos que indicam a grande quantidade de casos envolvendo violência sexual no âmbito intrafamiliar, isso também implica a observação de qual relação que o agressor possui com a pessoa violentada. 0 incesto se trata de relação sexualizada que ocorre entre pessoas da mesma família. Como possível causa da dinâmica familiar incestuosa está a crise da estrutura familiar (PÖTTER, 2016). Em conjunto, as condições econômicas e sociais

6 Em tradução livre, "Stranger Things" significa "coisas mais estranhas". A série é uma produção da provedora global Netflix e possui, até o mês de junho de 2020, três temporadas. A ficção científica se desenvolve a partir do desaparecimento de um garoto, quando, então, toda a cidade empreende buscas para encontrá-lo. Contudo, o que se apresenta são segredos, forças sobrenaturais e uma menina. 
também exercem influência, a exemplo da insuficiência de espaço físico e do uso de substâncias psicoativas (com ênfase para o álcool). Em termos específicos, o incesto também é conhecido como abuso sexual intrafamiliar.

A presença de crises conjugais, bem como a falta de amor dos genitores ou responsáveis, pai ou mãe sexualmente perturbados, subversão das normas, valores e expectativas sociais dos membros familiares acabam fragilizando as relações e propiciam a violência que amotina os membros da família, em especial as crianças e os adolescentes. A disfuncionalidade na estrutura familiar, dessa forma, pode levar ao incesto. (PÖTTER, 2016, p. 69).

A pedofilia e o incesto como práticas sociais contemporâneas desviantes revelam-se presentes não apenas no segmento televisivo, mas também musical, com aceitação popular que leva a crer na falta de percepção social da pretensão das letras. Na linha do já exposto, acerca do duplo cenário que se observa no Brasil, por infantes gozarem de proteção legislativa ao mesmo tempo em que há incentivo à exposição de seus corpos, a banda gaúcha "Bidê ou Balde"7 lançou no ano de 2000 uma canção que se tornou polêmica. A letra da música, denominada de "E por que não?", foi alvo de discussão por fazer apologia à pedofilia e ao incesto, bem como por banalizar a violência contra infantojuvenis:

Eu estou amando a minha menina

E como eu adoro suas pernas fininhas

Eu estou cantando pra minha menina

Pra ver se eu convenço ela a entrar na minha

E por que não?

Teu sangue é igual ao meu, é igual ao meu

Teu nome fui eu quem deu

Te conheço desde que nasceu

E por que não?

Eu estou adorando

Ver a minha menina

Com algumas colegas

Dela da escolinha

Eu estou apaixonado

Pela minha menina

0 jeito que ela fala, olha,

0 jeito que ela caminha.

(BEOLCHI, 2018, s.p.).

A evidência do incentivo ao incesto se dá, enfaticamente, quando a letra menciona " $E$ por que não?", se teu sangue é igual ao meu, se teu nome fui eu quem deu, deixando claro um vínculo de filiação entre aquele que fala e a menina (a de pernas fininhas, acompanhada das colegas). A oitiva da letra musical gera desgosto, vez que o caráter de um certo desejo 
nutrido por um pai pela sua filha, o qual objetiva que a infante "entre na minha". Inegável, portanto, a referência, o incentivo e a banalização da violência sexual intrafamiliar.

Diante da flagrante ofensa a direitos fundamentais infantojuvenis, o Ministério Público do Estado do Rio Grande do Sul, por intermédio da Promotoria Especializada da Infância e da Juventude da Comarca de Porto Alegre, promoveu Ação Civil Pública em face do grupo musical, da Acit Comercial Fonográfica e da Sony Music Entertainment. Em acesso ao teor decisório de recurso de agravo de instrumento ${ }^{8}$, interposto pelo parquet, julgado pela Sétima Câmara Cível do Tribunal de Justiça gaúcho, em dezembro de 2005, observa-se que foi parcialmente provido. 0 objetivo consistia em, liminarmente, obter a proibição de divulgação de CD’s da Banda Bidê ou Balde ("Acústico MTV Bandas Gaúchas" e "Se Sexo é o Que importa, só o Rock é sobre Amor"), além de faixa da referida música que constava em DVD, através dos veículos de comunicação do estado, sob pena de incidência de multa diária em prol do Fundo Estadual dos Direitos da Criança e do Adolescente. Ainda, postulava-se em caráter de antecipação de tutela a notificação das gravadoras e da banda para publicação de nota em imprensa, assim como recolhimento do conteúdo digital em mercado, sob pena de multa (RIO GRANDE DO SUL, 2018). Cumpre transcrever trecho da fundamentação exposta pelo Relator (Desembargador Ricardo Raupp Ruschel), que bem analisou a ótica aqui visada:

Como se vê, não se trata, à evidência, de poesia de amor paternal, senão que amor carnal "pela minha menina", já que nenhum pai nutre "adoração de suas pernas fininhas" e nem precisa "cantar... pra ver se eu convenço ela a entrar na minha". Ratifica tal interpretação a circunstância da conhecida supressão, do texto original, da palavra "não" dos versos do refrão: "Teu sangue (não) é igual ao meu... Teu nome (não) fui eu quem deu....", revelando-se efetiva confissão do propósito provocativo, atentatório e criminoso, ofendendo os direitos fundamentais à dignidade, ao respeito e à liberdade, como pessoas humanas, das crianças e adolescentes, tão claramente estabelecidos no artigo 227, caput, da CF, e ratificados nos artigos $3^{\circ}$ e $4^{\circ}$ da Lei 8.069/90. (RIO GRANDE DO SUL, 2018, s.p.).

Em complemento, o Desembargador Luiz Felipe Brasil Santos narra que se faz necessário "[...] atentar que a letra musical em exame, apesar de não ser ostensivamente pornográfica, é mais grave do que isso, pois contém uma clara sugestão de que a pedofilia e o incesto são comportamentos perfeitamente aceitáveis ('E por que não?')", e complementa: "quando sabemos todos que se trata de uma manifestação doentia de personalidade (tecnicamente uma 'perversão'), que causa em suas vítimas profundos e indeléveis traumas, que carregarão por toda a vida" (RIO GRANDE DO SUL, 2018, s.p.).

A inserção da violência sexual no ambiente familiar nem sempre é acompanhada pela força. Por vezes, é naturalizada, o que ocorre sem a percepção de sua ocorrência, principalmente quando se está a falar de crianças, diante do desenvolvimento cognitivo peculiar. Ao mesmo tempo, deve ser levada em consideração a representação psicológica da figura paterna (autoridade para o infante), além de que o genitor representa o justo, correto e ideal portador do discurso da verdade (o que pode fazer parecer que o incesto é algo normal). Desse modo, a existência e a aceitação de letra musical que incentiva o incesto pode se tornar ainda mais pernicioso no contexto da violência intrafamiliar, porque corroboram a acei- 
tabilidade e a normalidade do abuso. A respeito, o eminente Desembargador Luiz Felipe tece que:

Atente-se para essa relevantíssima observação acerca de que a denominada "coerção sutil" constitui, em muitos casos, a estratégia dos pais incestuosos. Com efeito, é justamente nesse contexto que obras, ditas "artísticas", como essa, se inserem, pois, na medida em que busca apresentar o incesto como algo absolutamente normal e aceitável ("E POR QUE NÃO?"), contribuem para que a "coerção sutil" alcance sua abjeta finalidade. Observe-se que para a criança, o pai, por ser a figura maior de autoridade, é o portador do discurso da verdade. Logo, o que ele diz é, em princípio, certo e justo. Dessa forma, especialmente em crianças de tenra idade, o incesto pode parecer, de início, algo absolutamente correto e normal, porque assim é apresentado pelo pai. Essa estratégia fica bastante reforçada se forem tidas como aceitáveis obras que buscam banalizar essa conduta. (RIO GRANDE DO SUL, 2018, s.p.).

Uma vez que o feito tramitou sob segredo de justiça, não foi possível apreciar os termos de sua sentença, posteriormente exarada. Contudo, em caráter liminar, não houve proibição à divulgação e à comercialização do conteúdo, mas restou imposta a necessidade de veicular que a letra contém estímulo e banalização à violência sexual contra crianças, além de multa sobre o faturamento. Atualmente a canção foi regravada, com algumas modificações.

Sutilmente, a convivência em coletividade é acompanhada do hábito histórico, cultural e social que sexualiza infantes. Velando pela dignidade infantil, o Conselho Nacional de Justiça, em outubro de 2017, lançou a campanha "Criança Não Namora", no intuito de provocar o debate sobre o tema em apreço, enraizado nas mais diversas sociedades (BRASIL, 2018). Tal comportamento, que precocemente atribui o desenvolvimento da sexualidade a crianças, representa o que se conhece por adultização, ou seja, a supressão da fase da infância e da adolescência pela inserção de concepções da vida adulta. Em contrapartida, mostra-se saudável ressaltar que a visibilidade de tais problemas ainda encontra muitos desafios, sobretudo no ambiente doméstico, no qual há dificuldades para um diálogo consciente e reflexivo. Até porque, a exemplo da prática do incesto, antes narrada, muitos desses atos corrosivos são praticados no seio de famílias desestruturadas ${ }^{9}$. Se já apresenta tal insucesso, o que afirmar a respeito da dignidade infantojuvenil?

Muitas das questões aqui discutidas, portanto, são ocultadas por dois modos, seja através do segredo que impera no ambiente violentador, seja através da ocultação social (com ênfase à indústria midiática). Torna-se cristalino um dos passos necessários para o enfrentamento da violência sexual (principalmente se considerada na sua esfera intrafamiliar): torná-la visível. E, para que seja descoberta, o rompimento do "pacto de silêncio" é imprescindível. Todavia, não se pode imputar apenas à pessoa ofendida a responsabilidade pelo enfrentamento do processo cruel que suporta, carece-se, desse modo, de medidas preventivas que enfrentem as causas do fenômeno, cuja profundidade vai muito além do que se aproxima aos olhares distraídos. O seu impedimento também necessita de importantes modificações no aspecto cultural, já que as práticas costumeiras mantêm arraigadas, desde

9 O sentido de "famílias desestruturadas", utilizado neste estudo, compreende a ideia de disfuncionalidade na estrutura familiar, através de indicadores como: crises conjugais, perturbações sexuais dos genitores, agressividade dos pais, subversão das normas e uso do álcool - para citar alguns exemplos, como os mencionados por Luciane Pötter (2016). 
longa data, a violência, sobretudo de gênero, marcada por relações de poder e de dominação, como especificamente observado em momento anterior (a respeito da cultura do estupro).

\section{CONSIDERAÇÓES FINAIS}

Considerada crime, evento traumático e até doença, a violência circunda por grandes campos, cuja ênfase traçada neste breve estudo se deu no sentido sociológico. A transcendência do fenômeno da violência sexual dos discursos exclusivos que a justificam no campo da (in)consciência humana, a sustentar patologias e desejos, permitiu repensá-la como fenômeno social, por intermédio da problemática de banalização da própria violência, do corpo feminino, das questões atinentes ao gênero, da cultura do estupro, entre outros.

No espaço social, muitas causalidades emergem por origens mais profundas do que as compreensões iniciais podem crer. Tratam-se de situações que no mais das vezes se desenvolvem de forma velada, dentre elas a violência, em especial na sua forma sexual. No intuito de discuti-la, especialmente a praticada contra crianças e adolescentes, senti-la e enfrentar a celeuma, que o presente trabalho foi desenvolvido.

No âmbito familiar e das relações próximas ao infantojuvenil concentram-se a maior parte dos casos do tipo, afetando igualmente as variadas classes sociais e econômicas. A própria violência, que se desdobra em tantos modos de ser, tem na forma sexual o extremo do caráter doloroso, se fazendo reiteradamente acompanhar de outras modalidades, como a psicológica. Nesse sentido é que se verifica o pacto de silêncio, grande característica do processo de violência intrafamiliar e que garante a sua manutenção. A pedofilia, por seu turno, trata-se de doença que acomete uma parcela dos abusadores, mas não a sua integralidade, e está presente de diversos modos no comportamento social, reproduzidos pelos meios de comunicação.

Em verdade, torna-se clara a erotização dos corpos infantis no cenário nacional, juntamente com a luta pela proteção integral e concretização de direitos humanos à população infantojuvenil. Constatou-se que, dos dados coletados pelo Ipea (2014), 88,5\% das ocorrências de estupro registraram vítimas do sexo feminino e mais da metade delas contava idade inferior a treze anos, o que, sem titubeações, é extremamente alarmante, haja vista as devastadoras consequências psicológicas, especialmente para pessoas em formação. Quanto ao autor, a maioria dos agressores é do sexo masculino, independentemente da idade da pessoa ofendida, cujos registros apontam para a autoria por parte de mulheres em menos de $2 \%$ dos casos (CERQUEIRA; COELHO, 2014). A mesma pesquisa também verifica que as pessoas próximas figuram, com frequência, como perpetradoras da violência (tais como pais, padrastos, amigos e conhecidos do núcleo familiar).

Na medida em que a idade da vítima aumenta, o indivíduo desconhecido se insere também neste horrendo rol, cujas causas variam e se acentuam em contextos de famílias disfuncionais (na acepção traçada por Luciane Pötter), com histórico de violência e perturbações de ordens psíquica e social. Contudo, tem-se ciência que, pelas particularidades dos crimes desta natureza, muitos fatos sequer chegam ao conhecimento dos órgãos públicos, a que se denomina de subnotificação. 
Tristemente, o processo vitimizatório não finda com o ato primário da violência, podendo vir a ocorrer o que se denomina de revitimização, consistente na repetição da violência, igualmente dolorosa à vítima, protagonizada pelos órgãos públicos responsáveis pela proteção da pessoa vitimizada e pela persecução penal. 0 espaço social, por vezes, também figura como repetidor da violência (a exemplo de quando culpabiliza a vítima). Além do silêncio, a identificação dos fatos encontra fortes obstáculos. O estupro, modo mais corrosivo da violência em tela, possui mais facilidade para ser caracterizado, isso em razão dos sinais físicos, cumprindo ressaltar que ele atinge não só meninas, mas também meninos, atualmente facilitado pela rede mundial de computadores.

Pela frequência e duração desse fenômeno, que acompanha a história da humanidade, é possível afirmar que questões culturais estão na raiz da problemática e se inserem nesse cenário pela desconsideração da condição humana de outrem, pela objetificação do ser através da violência e pela dominação dos corpos como típico comportamento da cultura patriarcal. Enfatizar a faceta social do problema não significa desconsiderar a relação com outros âmbitos, o que foi salientado constantemente no estudo. 0 intuito, nesse sentir, é refazer o trajeto dominado pelo discurso hegemônico, de que determinadas condutas encontram amparo exclusivo na lógica patológica e de desejo, para, então, possibilitar compreender como a cultura e as relações humanas criam conflitos e são omissas às situações de amargor e consternação. Tornar o problema visível é um grande avanço, e para isso, mostra-se necessário discuti-lo.

\section{REFERENCIAS}

ALVAREZ, Rachel. A adultização de Millie Bobby Brown. Coletivo Não Me Kahlo, [s. I.], 11 nov. 2017. Disponível em: https://naomekahlo.com/a-adultizacao-de-millie-bobby-brown/. Acesso em: 23 nov. 2017.

ANDRADE, Vera Regina Pereira de. A soberania patriarcal: o sistema de justiça criminal no tratamento da violência sexual contra a mulher. Revista Seqüência, Florianópolis, v. 26, n. 50, p. 71-102, jul. 2005.

BARATTA, Alessandro. Direitos Humanos: entre a violência estrutural e a violência penal. Fascículos de Ciências Penais, Porto Alegre, v. 06, n. 2, p. 44-61, abr./maio/jun. 1993.

BEOLCHI, Renato. Bidê ou Balde é acusada de apologia à pedofilia. Terra, 21 jul. 2005. Disponível em: http:// musica.terra.com.br/interna/0,OI600005-El1267,00-Bide+ou+Balde+e+acusada+de+apologia+a+pedofilia.html. Acesso em: 2 mar. 2018.

BOURDIEU, Pierre. O poder simbólico. Tradução de Fernando Tomaz. Lisboa: Difusão Editorial; Rio de Janeiro: Bertrand Brasil, 1989.

BRASIL. Conselho Nacional de Justiça. Mês da criança: CNJ na proteção de crianças e adolescentes. Brasília, 11 out. 2017. Disponível em: http://www.cnj.jus.br/noticias/cnj/85504-mes-da-crianca-cnj-na-protecao-de-criancas-eadolescentes. Acesso em: 3 mar. 2018.

BRASIL. Constituição da República Federativa do Brasil de 1988. Diário Oficial [da República Federativa do Brasil], Brasília, DF. Disponível em: http://www.planalto.gov.br/ccivil_03/constituicao/constituicaocompilado.htm. Acesso em: 20 abr. 2020(a).

BRASIL. Lei $n^{\circ}$ 11.340, de 07 de agosto de 2006. Cria mecanismos para coibir a violência doméstica e familiar contra a mulher, dentre outros. Diário Oficial [da República Federativa do Brasil], Brasília, DF, ano CXLIII, n 151, 08 de agosto de 2006. Seção 1, p. 1-4. Disponível em: http://www.planalto.gov.br/ccivil_03/_ato2004-2006/2006/ lei/I11340.htm. Acesso em: 10 mar. 2020(b). 
BRASIL. Lei n 13.431, de 04 de abril de 2017. Estabelece o sistema de garantia de direitos da criança e do adolescente vítima ou testemunha de violência e altera a Lei n 8.069/90. Diário Oficial [da República Federativa do Brasil], Brasília, DF, ano CLIV, nº 66, 05 de abril de 2017. Seção 1, p. 1-3. Disponível em: http://www.planalto.gov. br/ccivil_03/_Ato2015-2018/2017/Lei/L13431.htm. Acesso em: 10 mar. 2020(c).

BRASIL. Lei n 8.069, de 13 de julho de 1990. Estatuto da Criança e do Adolescente. Diário Oficial [da República Federativa do Brasil], Brasília, DF, ano CXXVIII, n 135, 16 de julho de 1990. Seção 1, p. 01-15. Disponível em: http://www.planalto.gov.br/ccivil_03/leis/L8069.htm. Acesso em: 20 abr. 2020(d).

BRASIL. Ministério da Saúde. Secretaria de Vigilância Sanitária. Boletim Epidemiológico, volume 49, n. 27, jun./2018. Disponível em: http://portalarquivos2.saude.gov.br/images/pdf/2018/junho/25/2018-024.pdf. Acesso em: 1 jun. 2019.

BURCKHART, Thiago. Gênero, dominação masculina e feminismo: por uma teoria feminista do Direito. Revista Direito em Debate, ljuí, ano XXVI, n. 47, p. 205-224, jan./jun. 2017.

CARAMIGO, Denis. Sim, pedofilia não é crime. Jusbrasil, Canal Ciências Criminais, [s. I.], 11 nov. 2017. Disponível em: https://canalcienciascriminais.jusbrasil.com.br/artigos/518445952/sim-pedofilia-nao-e-crime?utm_ campaign=newsletter-daily_20171109_6278\&utm_medium=email\&utm_source=newsletter. Acesso em: 12 nov. 2017.

CASTRO, Joelíria Vey de; BULAWSKI, Cláudio Maldaner. O perfil do pedófilo: uma abordagem da realidade brasileira. Revista Liberdades, São Paulo, n. 6, p. 3-26, jan./abr. 2011.

CERQUEIRA, Daniel; COELHO, Danilo de Santa Cruz. Estupro no Brasil: uma radiografia segundo os dados da Saúde (versão preliminar). Brasília: IPEA, 2014. Disponível em: http://www.ipea.gov.br/portal/images/stories/ PDFs/nota_tecnica/140327_notatecnicadiest11.pdf. Acesso em: 6 nov. 2017.

CHAUI, Marilena de Souza. Ética e violência. Revista Teoria e Debate, São Paulo, v. 39, 1998. Disponível em: https:// teoriaedebate.org.br/1998/10/01/etica-e-violencia/. Acesso em: 29 set. 2019.

CHILDHOOD BRASIL. Entenda a diferença entre abuso e exploração sexual. [S. I.], 24 jan. 2013. Disponível em: http://www.childhood.org.br/entenda-a-diferenca-entre-abuso-e-exploracao-sexual. Acesso em: 6 nov. 2017.

COLLUCCI, Claudia. País registra 10 estupros coletivos por dia; notificações dobram em 5 anos. Folha de São Paulo, São Paulo, 20 ago. 2017. Disponível em: https://www1.folha.uol.com.br/cotidiano/2017/08/1911346-pais-registra-10-estupros-coletivos-por-dia-notificacoes-dobram-em-5-anos.shtml. Acesso em: 6 nov. 2017.

DEBORA. Millie Bobby Brown e a problemática da adultização de meninas. Valkirias, [s. I.], 13 abr. 2018. Disponível em: http://valkirias.com.br/millie-bobby-brown/. Acesso em: 5 jun. 2020.

DUSSEL, Enrique D. 16 Tesis de economía política: una filosofía de la economía. Buenos Aires: Docencia, 2013. p. 13-82. Disponível em: https://bit.ly/2k13Gpd. Acesso em: 5 set. 2019.

FALEIROS, Vicente de Paula. A violência sexual contra crianças e adolescentes e a construção de indicadores: a crítica do poder, da desigualdade e do imaginário. Revista SER Social, [s. I.], n. 2, p. 37-56, mar. 1998.

FELIPE, Jane. Pedofilização como prática social contemporânea nos sites para crianças. Revista Direitos Humanos (Secretaria de Direitos Humanos da Presidência da República), Brasília, v. 08, p. 31-34, jan. 2012.

GIDDENS, Anthony. Sociologia. Tradução de Alexandra Figueiredo, Ana Patrícia Duarte Baltazar, Catarina Lorga da Silva, Patrícia Matos e Vasco Gil. 6. ed. Lisboa: Fundação Calouste Gulbenkian, 2008.

LARA, Bruna de; RANGEL, Bruna; MOURA, Gabriela; BARIONI, Paola; MALAQUIAS, Thaysa. \#MeuAmigoSecreto: feminismo além das redes. Rio de Janeiro: Edições de Janeiro, 2016.

MARCONI, Marina de Andrade; LAKATOS, Eva Maria. Fundamentos de metodologia científica. 5. ed. São Paulo: Atlas, 2003.

MINAYO, Maria Cecília de S. A violência social sob a perspectiva da saúde pública. Cadernos de Saúde Pública, Rio de Janeiro, v. 10, supl. 01, p. 7-18, 1994. Disponível em: http://www.scielo.br/pdf/csp/v10s1/v10supl1a02. pdf. Acesso em: 29 set. 2017. 
MOROTTI, Carlos. Vitimização primária, secundária e terciária. Jusbrasil, Canal Ciências Criminais, [s. I.], 2015. Disponível em: https://morotti.jusbrasil.com.br/artigos/210224182/vitimizacao-primaria-secundaria-e-terciaria. Acesso em: 30 set. 2017.

NIELSSON, Joice Graciele; WERMUTH, Maiquel Ângelo Dezordi. A "carne mais barata do mercado": uma análise biopolítica da "cultura do estupro" no Brasil. Revista da Faculdade de Direito da UERJ, Rio de Janeiro, n. 34, p. 171200, dez. 2018. Disponível em: https://www.e-publicacoes.uerj.br/index.php/rfduerj/article/view/26835. Acesso em: 25 fev. 2020.

OPAS. OMS divulga nova Classificação Internacional de Doenças (CID 11). Organização Pan-Americana da Saúde, Brasil, jun. 2018. Disponível em: https://www.paho.org/bra/index.php?option=com_ content\&view=article\&id=5702:oms-divulga-nova-classificacao-internacional-de-doencas-cid-11\&ltemid=875. Acesso em: 5 jul. 2020.

PAGANELLA, Eduardo. Decretada prisão preventiva de homem apontado como autor de abuso sexual em supermercado em Porto Alegre. Zero Hora, Porto Alegre, 25 set. 2017. Disponível em: https://gauchazh.clicrbs.com. br/seguranca/noticia/2017/09/decretada-prisao-preventiva-de-suspeito-de-abusar-menina-dentro-de-supermercado-em-porto-alegre-cj8012yn900je01lhs9uaegw8.html. Acesso em: 29 set. 2017.

PAPLOWSKI, Schirley Kamile. Onde foi parar meu anjo da guarda? O panorama brasileiro da violência sexual infantojuvenil e seus decorrentes impactos jurídicos e psíquicos. 2018. Trabalho de Conclusão de Curso (Bacharelado em Direito) - Universidade Regional do Noroeste do Estado do Rio Grande do Sul, Três Passos, 2018. Disponível em: http://bibliodigital.unijui.edu.br:8080/xmlui/handle/123456789/5487. Acesso em: 28 mar. 2020.

PÖTTER, Luciane. Vitimização secundária infantojuvenil e violência sexual intrafamiliar: por uma política pública de redução de danos. 2. ed. rev. e atual. Salvador: JusPODIVM, 2016.

QUINTANA, Mario. A cor do invisível. 2. ed. São Paulo: Globo, 2005.

RIO GRANDE DO SUL. Tribunal de Justiça do Rio Grande do Sul. Agravo de Instrumento nº 70013141262 . Agravo de instrumento. Ação civil pública. Letra de música que faz apologia à pedofilia e ao incesto. Antecipação de tutela. Possibilidade, em termos. Inegável que a letra da música "E por que não", da banda "Bidê ou Balde", materializa apologia ao incesto e à pedofilia, sendo impossível, material e constitucionalmente, a pura e simples extirpação do material do universo social, já entranhada nos lares e à disposição em centenas de"sites" na Internet. Hipótese de reconhecimento judicial da ofensa, com minimização de seus efeitos, com aplicação de multa, por veiculação e decorrente de parcela dos lucros, em benefício de órgão estadual de bem estar do menor. Recurso parcialmente provido, por maioria. Sétima Câmara Cível, Relator: Desembargador Ricardo Raupp Ruschel, julgado em 07 de dezembro de 2005. Disponível em: https://www.tjrs.jus.br/buscas/jurisprudencia/exibe_html.php. Acesso em: 2 mar. 2018.

SANFELICE, Mirela Massia. Violência de gênero: um estudo das relações de gênero de homens autores de abuso sexual contra crianças em Santa Maria. Santa Maria: UFSM, 2011. 116 p. Dissertação (Mestrado) - Programa de Pós-Graduação Stricto Sensu em Ciências Sociais, Centro de Ciências Sociais e Humanas, Universidade Federal de Santa Maria, Santa Maria, 2011.

SPERB, Paula. No RS, estudante de medicina é preso em flagrante por pedofilia. Revista Veja, Rio Grande do Sul, 19 set. 2017. Disponível em: http://veja.abril.com.br/blog/rio-grande-do-sul/no-rs-estudante-de-medicina-e-preso-em-flagrante-por-pedofilia/\#. Acesso em: 29 set. 2017.

VIEIRA, Monique Soares. A interface entre a violência sexual contra crianças e adolescentes e a violência de gênero: notas críticas acerca do cenário do município de Porto Alegre. Revista Margens Interdisciplinar, [s. I.], v. 9, n. 12, p. 254-269, maio 2016. Disponível em: http://www.periodicos.ufpa.br/index.php/revistamargens/article/ view/3075/3096. Acesso em: 11 nov. 2017.

Recebido/Received: 25.04.2020.

Aprovado/Approved: 09.07.2020. 